\title{
Ophthalmic herpes zoster with severe complications in an immunocompromised patient: A case report and review of the literature
}

\author{
GABRIELA MARIANA IANCU ${ }^{1,2}$, DAN MIRCEA STĂNILĂ $\breve{~}^{3,4}$, REMUS CĂLIN CIPĂIAN ${ }^{5,6}$ and MARIA ROTARU ${ }^{1,2}$ \\ ${ }^{1}$ Department of Dermatology, Faculty of Medicine, Lucian Blaga University, 550169 Sibiu; ${ }^{2}$ Clinic of Dermatology, \\ County Emergency Hospital of Sibiu, 550245 Sibiu; ${ }^{3}$ Department of Ophthalmology, Faculty of Medicine, \\ Lucian Blaga University, 550169 Sibiu; ${ }^{4}$ Clinic of Ophthalmology, County Emergency Hospital of Sibiu, \\ 550245 Sibiu; ${ }^{5}$ Department of Internal Medicine, Faculty of Medicine, Lucian Blaga University, 550169 Sibiu; \\ ${ }^{6}$ Clinic of Internal Medicine, County Emergency Hospital of Sibiu, 550245 Sibiu, Romania
}

Received September 1, 2021; Accepted October 1, 2021

DOI: $10.3892 / \mathrm{etm} .2022 .11138$

\begin{abstract}
The increasing incidence for herpes zoster, including its ophthalmic form, is based on physiological (senescence) and acquired immunosuppression, particularly under oncologic treatment. The immunocompromised status of the patient favors the appearance of severe complications. The patient, aged 54, with chronic lymphocytic leukemia, presented 1 week from the onset with an erythematous, vesicular-bullous rash on the right trigeminal nerve's ophthalmic dermatome, marked edema, intense pain and large submandibular ganglion masses. There were cutaneous (necrotic ulcerations superinfected with methicillin-resistant Staphylococcus aureus), ocular (keratoconjunctivitis, total ophthalmoplegia, lagophthalmia, anterior hemorrhagic uveitis with hyphema and right eye blindness) and neurological (postherpetic neuralgia) complications. Systemic therapy was performed with acyclovir, antibiotics, supportive, rebalancing and symptomatics. With regards to treatment for skin ulcers, disinfection and necrectomy were performed, and epithelialization agents were subsequently administrated. At the ocular level, the ophthalmologist carefully monitored the patient and administered antivirals, antibiotics, epithelialization agents and autologous serum. The evolution of the case recorded severe, disabling complications, with extensive eyelid necrosis and definitive blindness. In this case, the severity of the ophthalmic herpes zoster (OHZ) was favored by the synergistic action of four factors: Acquired immunosuppression (chronic lymphocytic leukemia), delayed consultation,
\end{abstract}

Correspondence to: Dr Remus Călin Cipăian, Department of Internal Medicine, Faculty of Medicine, Lucian Blaga University, Street Lucian Blaga 2A, 550169 Sibiu, Romania

E-mail: calin.cipaian@ulbsibiu.ro

Key words: ophthalmic herpes zoster, complications, immunocompromised, necrotic ulcer, lymphocytic leukemia superinfectious lesions and patient non-compliance regarding the chronic lymphocytic leukemia treatment.

\section{Introduction}

Ophthalmic herpes zoster (OHZ) is a frequent localization of zoster ( $1 / 5$ of cases) that is characterized by typical vesicular lesions arranged on an erythematous-edematous background along the path of the trigeminal nerve ophthalmic branch (1). $\mathrm{OHZ}$ is five times more frequent than the mandibular and maxillary branches' damage (2). The impairment of the nasociliary ramification (ophthalmic branch) is clinically expressed by the Hutchinson sign (specific lesions on the lateral edge of the nasal pyramid up to the tip of the nose), and predicts ocular damage (3).

The increasing incidence for herpes zoster, including $\mathrm{OHZ}$, may be due to immunosenescence (increased risk after 60 years) and acquired immunosuppression [the increasing number of neoplasms (particularly haematologic)], transplanted and patients infected with human immunodeficiency virus (HIV), the use of immunosuppressive, chemotherapeutic, biological therapies, systemic corticosteroids for long periods, virulence of the varicella-zoster virus $(\mathrm{VZV})$ and the general immune status of the patient (4).

In $\mathrm{OHZ}$, acquired immunosuppression is frequently induced by organ transplants and immunosuppressive therapies, HIV infection (15-25 times higher) and neoplasms (5). $\mathrm{OHZ}$ may present with severe forms in immunosuppressed patients, with long, exhaustive evolutions, which require early systemic therapies with permanent monitoring of potential complications (6). Delayed referrals to specialist doctors and cataract surgery favour the severe forms of $\mathrm{OHZ}(7,8)$. $\mathrm{OHZ}$ has a higher risk of developing ocular complications; before antiviral therapy the risk was $50 \%$ and now the risk has decreased to under $29 \%$ (1).

The most common complications associated with $\mathrm{OHZ}$ are cutaneous, including ulcerations, cellulitis, vicious scars in necrotic forms, ectropion, entropion and risk of bacterial superinfections with multi-resistant germs, such as 
methicillin-resistant Staphylococcus aureus (MRSA) and Pseudomonas aeruginosa (9).

Ocular complications can be diverse, from mild, reversible to severe complications resulting in irreversible blindness. The following may occur at the oculo-palpebral level: Episcleritis, scleritis, keratitis, conjunctivitis, iridocyclitis, anterior and posterior uveitis, ciliary body ischemia, secondary glaucoma, vitritis, cataracts, pupillary lesions (Horner syndrome), paralysis of cranial nerves (III, IV-VI), orbital apex syndrome, orbital abscess, lesions of the optic nerve (optic nerve atrophy, retrobulbar optic neuropathy) or retinal lesions (hemorrhagic retinitis, acute retinal necrosis, choroiditis, branchial or central retinal artery obstruction and retinal detachment) $(6,10)$. Acute retinal necrosis is often caused by VZV and presents as acute iridocyclitis, inflammation of the vitreous body, necrotizing retinitis, occlusive retinal vasculitis, rapid loss of vision and retinal detachment (11).

Among the neurological complications in $\mathrm{OHZ}$, the most common is postherpetic neuralgia, which increases with age (36.6\% of patients with $\mathrm{OHZ}$ are $>60$ years; $47.5 \%$ of patients with ophthalmic herpes are $>70$ years) (12). Following the remission of acute infection, chronic inflammation persists in the trigeminal area, with perineural lymphocyte infiltrates (trigeminal tract and mesencephalic nucleus) lasting months or years after the eruption of OHZ (12). Manifestation of postherpetic neuralgia decreases with time, reaching $30 \%$ at 6 weeks and 9\% 1 year after onset (13). Other neurological complications include cranial nerves (III, IV and VI) palsies, Ramsay-Hunt syndrome, palpebral ptosis, sympathetic ophthalmia, contralateral hemiplegia, encephalitis and myelitis $(12,14,15)$. In severe forms of zoster, mortality can be high, particularly in disseminated types (5-15\%) (16).

The antiviral agents (for example, acyclovir) inhibits viral DNA polymerase, thus decreasing viral replication (17). Therefore, the oral antiviral therapies or intravenous antiviral agents (for severe forms or for patients who are immunosuppressed) decrese complications in OHZ.

\section{Case report}

A male, aged 54 years old, diagnosed with chronic lymphocytic leukemia (CLL), failed to attend follow-up consultations for 1 year. The patient was admitted to the Emergency Hospital of Sibiu County's Dermatology Clinic in August 2016 due to an extensive, extremely painful, erythematous, vesicular-bullous rash, marked edema of the right fronto-orbital level and half of the scalp, impossibility of opening the palpebral cleft and high-intensity headaches (Fig. 1A), which debuted 1 week prior. Following admission, the patient had subfebrile temperature $\left(37.5^{\circ} \mathrm{C}\right)$, with large, painful, hard lymph nodes, adherent to the superficial and deep planes on the right side of the submandibular area.

Ophthalmologic examination of the right eye (RE) revealed conjunctival changes (chemosis, mixed conjunctival hyperemia and purulent conjunctival secretion), at the level of the anterior pole corneal changes (epithelial and stromal edema, and hypotransparency of the cornea), palpebral changes (hard edema and erythematous-vesicular-bullous rash) and protrusion of the eyeball. The posterior pole was difficult to examine due to severity of the swollen eyelids and hypotransparency of the cornea. In both eyes, fine crystalline densifications were present; however, motility was preserved in all quadrants. Examination of the left eye (LE) was within normal limits. Laboratory investigations confirmed the leukemic status (leukocytes, $120,000 / \mathrm{mm}^{3}$ ), inflammatory syndrome and superinfection of ulcerations with MRSA.

After $24 \mathrm{~h}$, eruption of the zoster disseminated. Within 3 days, the lesions rapidly evolved towards deep, necrotic ulcerations, extending in the periphery and depth, at the right fronto-parietal level (Fig. 1B), including the palpebral level, where it caused palpebral retraction and lagophthalmia. Ophthalmological examination revealed decreased visual acuity ofthe RE (at $50 \mathrm{~cm}$ ), RE hypotransparency in $2 / 3$ inferior cornea, chemosis, immobile eyeball, semimydriasis, fixed/non-reflexive pupils, exophthalmia (RE, $23 \mathrm{~mm}$; LE, $16 \mathrm{~mm}$ ) and RE complete ophthalmoplegia (Fig. 2A).

Given the severity of the disease and immunosuppressed status induced by CLL, acyclovir was injected at $3 \times 750 \mathrm{mg} / \mathrm{day}$ for 7 days, followed by oral therapy with $4 \mathrm{~g}$ /day of acyclovir for an additional 10 days. This therapy was associated with systemic anti-inflammatory, antialgic treatment, opioids, antiepileptics, antibiotics (gentamicin $160 \mathrm{mg} /$ day for 7 days + cotrimoxazole $4 \times 480 \mathrm{mg} / \mathrm{day}$ for 14 days), antifungals and group B vitamin therapy. Necrectomy and disinfection with antiseptic solutions were performed locally, as well as application of epithelializing ointments with Kanamycin sulfate. Simultaneously, the patient was evaluated and treated by the ophthalmologist with topical ocular antivirals (acyclovir), antibiotics (chloramphenicol), epithelializing (vitamin A and guma xantan) and mydriatic agents (Tropicamide). Resumption of chemotherapy was unable to be performed for CLL due to the risk of viral multiplication and the possibility of other complications.

After 1 month, the patient was discharged with fronto-parietal granular ulcerations, palpebral scar-like retractile ulcerations, alopecia of RE eyelashes and eyebrows and significant reduction of RE visual acuity (Fig. 1C). The patient was admitted in September 2016 to the Ophthalmology Clinic for ocular pain, marked photophobia and almost complete loss of visual acuity in the RE (the patient perceived hand movement) 1 week after discharge. RE examination revealed abundant conjunctival secretion, corneal and conjunctival hypoesthesia, corneal ulcer in the half lower part of the cornea, with high permeability to fluorescein and peripheral corneal neovascularisation (Fig. 2B). Furthermore, the patient presented low RE visual acuity, perceived hand movements and hyphema (4-5 $\mathrm{mm}$ blood in the inferior part of anterior chamber). Intraocular tension was within normal limits (RE, $14 \mathrm{~mm} \mathrm{Hg}$; LE, $18 \mathrm{~mm} \mathrm{Hg}$ ), which excluded the diagnosis of secondary glaucoma. MRSA was isolated from the conjunctival secretion, with the same spectrum of sensitivity as during the previous admission. In this case, the corneal ulcer was complicated by the anterior hemorrhagic uveitis and the disciform keratitis that evolved unfavorably towards the neurotrophic keratitis superinfected with MRSA. At the fronto-parietal level, there were ulcerations covered by yellow, adherent and painful crusts.

The systemic therapy included 3 weeks of antivirals, antibiotics (cotrimoxazole for 2 weeks), antifungals and group B vitamins. Topical antibiotics and epithelizing agents were 
A

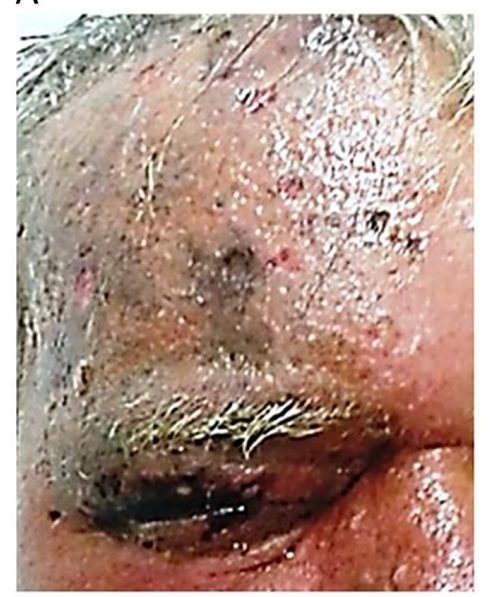

B

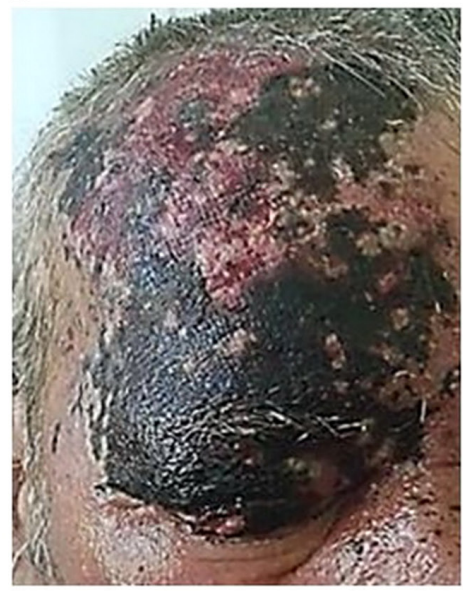

C

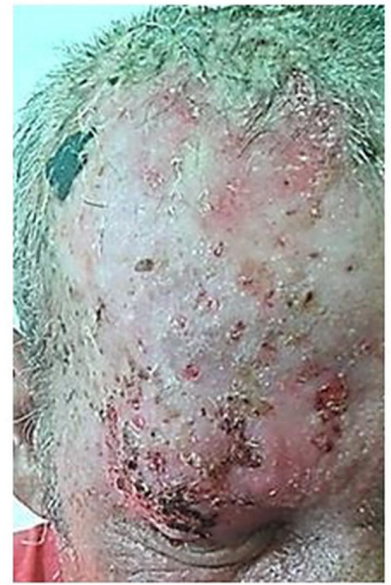

Figure 1. Clinical aspects of herpes zoster. Clinical aspect of herpes zoster (A) at admission, (B) 3 days of hospitalization and (C) on discharge, after 1 month.
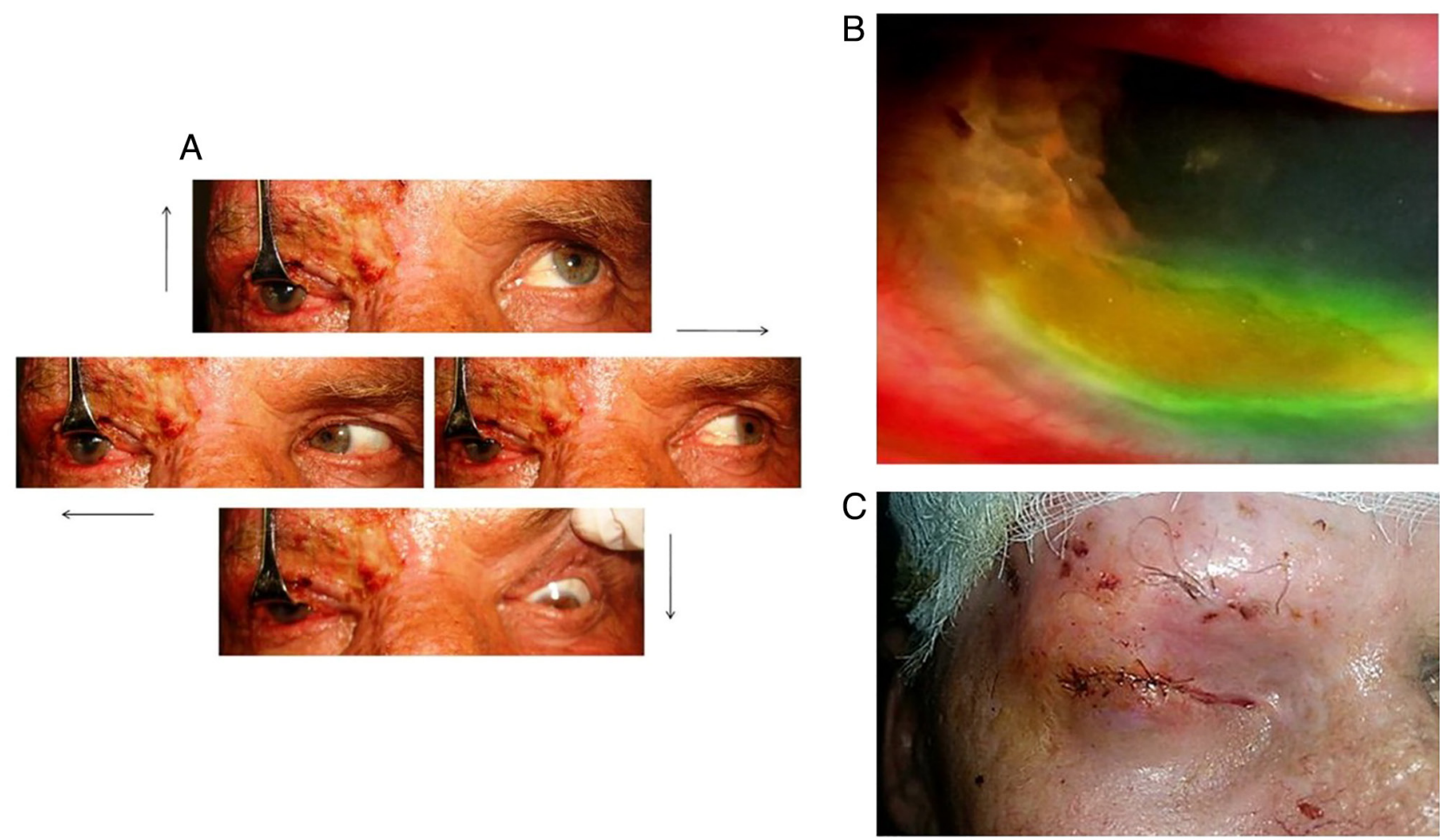

Figure 2. Ocular complications in the present study. (A) Complete ophthalmoplegia of the right eye.(B) Corneal ulcer, exposure keratopathy. (C) Blepharorrhaphy following necrosis of the upper eyelid reconstructed from the lower eyelid.

applied on the ulcerations. Corneal epithelialization agents, heparinized blood sample of the patient, glucose solution and other nutrients were administered on the ocular surface. After 3 weeks of treatment, the patient presented with a persistent corneal epithelial defect in $2 / 3$ of the lower part, hyphema of smaller dimensions $(\sim 0.5 \mathrm{~mm})$, lagophthalmia due to persistent upper eyelid necrosis, ophthalmoplegia and fronto-parietal granular ulcerations. Thus, blepharoraphy (a type of surgery, which is performed to maintain the anatomical integrity of the eyeball) was performed to prevent corneal ulcerations that may have resulted in perforation and loss of the eyeball. Blepharoraphy was performed to restore the necrotic upper eyelid and inferior eyelid (Fig. 2C).
After 2 months, the patient returned with partially epithelialized ulcerations of the scalp, with blepharoraphy and was referred to the Department of Hematology from County Emergency Hospital of Sibiu (Romania), for CLL therapy. Table I lists the complications associated with OHZ.

\section{Discussion}

OHZ appears in $1 / 5$ of all cases with herpes zoster, accompanied by potential skin, ocular, neurological or visceral complications (1). Reactivation, multiplication and retrograde migration of VZV along the trigeminal nerve pathway (ophthalmic branch) is clinically expressed by a specific eruption on the 
Table I. Complications associated with ophthalmic herpes zoster (OHZ) in different types of cancer.

\begin{tabular}{|c|c|c|c|c|c|c|}
\hline Authors, year & $\begin{array}{l}\text { Case } \\
\text { report no. }\end{array}$ & Age, years & Sex & Cancer & Complications & (Refs.) \\
\hline Cheema et al, 2019 & 1 & 63 & M & B-cell lymphoma & $\begin{array}{l}\text { Necrotic ulcers on tri-segmental } \\
\text { CN V distribution, trismus, right } \\
\text { CN III and IV palsies, endotheliitis, } \\
\text { iridocyclitis and blepharoconjunctivitis }\end{array}$ & $(18)$ \\
\hline Srinivasan et al, 2009 & 2 & 66 & $\mathrm{~F}$ & Breast cancer & Meningoencephalitis & (19) \\
\hline $\begin{array}{l}\text { Harthan and Borgman, } \\
2013\end{array}$ & 3 & 84 & $\mathrm{~F}$ & Breast cancer & CN III palsy with ophthalmoplegia & $(20)$ \\
\hline \multirow[t]{3}{*}{ Khalafallah et al, 2013} & 4 & 72 & $\mathrm{~F}$ & Multiple myeloma & $\begin{array}{l}\text { Herpetic neuralgia, conjunctivitis and } \\
\text { corneal pseudodendrites }\end{array}$ & $(21)$ \\
\hline & 5 & 50 & $\mathrm{~F}$ & Multiple myeloma & Optic neuritis & $(21)$ \\
\hline & 6 & 68 & M & Multiple myeloma & Postherpetic neuralgia & $(21)$ \\
\hline $\begin{array}{l}\text { Rajkumar and Baum, } \\
2016\end{array}$ & 7 & 71 & $\mathrm{~F}$ & $\begin{array}{l}\text { Uterine and } \\
\text { thyroid cancers }\end{array}$ & Cerebral venous sinus thrombosis & $(22)$ \\
\hline $\begin{array}{l}\text { Letchuman and Donohoe, } \\
2019\end{array}$ & 8 & 62 & M & Laryngeal cancer & $\begin{array}{l}\text { Ramsey-Hunt syndrome, left CN VI } \\
\text { and VII palsies, diplopia and } \\
\text { conductive hearing loss }\end{array}$ & (23) \\
\hline Mercier et al, 2019 & 9 & 68 & M & $\begin{array}{l}\text { Lung } \\
\text { adenocarcinoma }\end{array}$ & Ramsey-Hunt syndrome & (24) \\
\hline Chen et al, 2016 & 10 & 63 & M & $\begin{array}{l}\text { Chronic } \\
\text { lymphocytic } \\
\text { leukemia }\end{array}$ & $\begin{array}{l}\text { Ramsey-Hunt syndrome and exposure } \\
\text { keratopathy }\end{array}$ & $(25)$ \\
\hline Pointdujour et al, 2014 & 11 & 70 & $\mathrm{~F}$ & $\begin{array}{l}\text { Chronic } \\
\text { lymphocytic } \\
\text { leukemia }\end{array}$ & Acute orbital syndrome & (26) \\
\hline Sanghvi et al, 2006 & 12 & 83 & $\mathrm{~F}$ & $\begin{array}{l}\text { Chronic } \\
\text { lymphocytic } \\
\text { leukemia }\end{array}$ & Cicatricial ectropion & $(27)$ \\
\hline
\end{tabular}

M, male; F, female; $\mathrm{CN}$, cranial nerve.

corresponding dermatome, with variable ocular damage that is mostly limited at the cornea. Under immunosuppression, particularly that acquired through neoplasms or immunosuppressive therapies, the risk of developing severe forms that evolve towards disabling complications, such as retractable scars, blindness and cranial nerve palsies, is higher compared with immunocompetent patients $(1,6)$.

Currently, there are only a few published cases of OHZ with multiple complications in patients with cancer (18-27). These published cases and additional articles were searched on PubMed using the following terms: 'Ophthalmic herpes zoster', 'cancer patients', 'multiple complications' and 'case report'. A total of 12 cases of complicated OHZ in patients with hematological, breast, uterine, thyroid, laryngeal and lung cancers were identified (Table I).

In the present study, considering the immunosuppression acquired by CLL as a major risk factor, the patient developed a severe form of $\mathrm{OHZ}$ with multiple complications (Table II). The rapid evolution of ulcers in a necrotic form suggests that $\mathrm{OHZ}$ is associated with ecthyma gangrenosum, induced by
Pseudomonas aeruginosa, due to immunosuppression (28). The bacteriological exam infirms this suspicion but confirms that ulcers were superinfected with MRSA.

Complete ophthalmoplegia (simultaneous paralysis of the three cranial nerves, III, IV and VI) is a rare complication (11-29\% of cases with OHZ) (20). Shin et al (29) performed a study at Moorfields Eye Hospital on 146 patients with $\mathrm{OHZ}$ who were $>50$ years and found that $6.82 \%$ of patients had ophthalmoplegia (2.73\% complete form; $2.05 \%$ unilateral form; $1.36 \%$ unilateral form associated with proptosis and $0.68 \%$ bilateral form with proptosis) (29).

Multiple cranial nerve paralysis in $\mathrm{OHZ}$ can be explained by the direct cytopathic effect of the virus, acting on surrounding neuronal tissues and inflammation of the trigeminal nerve due to VZV reactivation that can spread through the cavernous sinus, thus affecting other nerves (30). At the vascular level, occlusive vasculitis may occur induced by the chronic inflammatory cellular changes of the virus (31).

In the present study, the cytopathic effect of VZV was aggravated by the immunosuppressed status and delayed treatment 
Table II. Severe and multiple complications developed by the patient in the present study.

A, Skin

Complication

Clinical manifestation

RE palpebral and right fronto-parietal necrotic ulcerations superinfected with MRSA

RE vicious palpebral scars

Extensive necrotic ulcerations in the right hemicranium

In evolution, by detaching the necrosis, the ulcerations healed with retractable scars and necrosis of the RE upper eyelid

B, Ocular

Complication

Herpetic keratoconjunctivitis

Complete ophthalmoplegia

Lagophthalmia

Anterior hemorrhagic uveitis with hyphema

RE blindness
Clinical manifestation

RE visual acuity to hand motion.

Chemosis, purulent conjunctival secretion.

Round oval areas of epithelial and stromal edema, descemet folds (signs specific to disciform keratitis, complication that usually appears late)

Right, immobile eyeball, semimydriasis, fixed and no reflexive pupil Lack of substance in the RE upper eyelid with defective confrontation of the eyelids, lagophthalmia, exposure keratopathy, corneal ulceration and require blepharorhaphy

Marked photophobia, semimydriasic pupil, fixed, non-reflexive, unevenly dilated, oval, anterior chamber with inflammatory reaction and 4-5 $\mathrm{mm}$ hyphema arranged inferiorly and nasally Loss of visual acuity in RE

C, Neurological

Complication

Clinical manifestation

Post-herpetic neuralgia

Painful headaches of increased intensity on the right hemicranium (unilaterally at the level of the scalp, forehead, upper eyelid and the middle third of the lower eyelid of RE, nose wing and right eyeball)

RE, right eye; MRSA, methicillin-resistant Staphylococcus aureus.

due to late presentation. Regarding the evolution of the corneal ulcer to anterior hemorrhagic uveitis, there are only a few cases of uveitis with hyphema reported (32-35). Hyphema, a complication of OHZ, has been reported in even fewer cases (36). The cause of bleeding is assumed to be a process of occlusive vasculitis (32).

In the analysis of the immediate prognosis, it is important to consider the risk of the corneal perforation of the ulcer, evolution towards corneal leukoma/loss of the eyeball, chronic ocular inflammation, acute retinal necrosis with the consecutive loss of vision and the orbital apex syndrome (37). In assessing the late prognosis, it is important to consider that postherpetic neuralgia can last for months/years, with an increased risk of the patient's immunosuppression (38). In addition, immunocompromised patients have a higher risk (40\%) of visceral dissemination, and the recovery of ophthalmoplegia is extremely difficult (may take 2-18 months) (4).
The prognosis was reserved due to the general oncological pathology, and the severe form of $\mathrm{OHZ}$ with multiple and severe ocular, cutaneous and neurological complications that developed.

In conclusion, in the present study, the severe form of $\mathrm{OHZ}$ was favored by non-timely referral of the patient to a medical service, the immunosuppression acquired through CLL and patient non-compliance with therapy. Thus severe $\mathrm{OHZ}$ with multiple complications, including cutaneous (ulceronecrotic, superinfected ulcers and scars), ophthalmologic (palpebral retraction and necrosis, lagophthalmia, kerato-conjunctivitis, total ophthalmoplegia, anterior hemorrhagic uveitis with hyphema and RE blindness) and neurologic (postherpetic neuralgia) occurred.

The peculiarity of this case consists of the extremely rare occurrence of complete ophthalmoplegia within the $\mathrm{OHZ}$ and 
the hyphema in the herpetic uveitis. This case is among the few of $\mathrm{OHZ}$ with multiple and severe complications in immunosuppressed cancer patients reported in the literature.

\section{Acknowledgements}

Not applicable.

\section{Funding}

No funding was received.

\section{Availability of data and materials}

The datasets used and/or analyzed during the current study are available from the corresponding author on reasonable request.

\section{Authors' contributions}

GMI was involved in research-creation and study design, analysis and interpretation of patient data, manuscript drafting and critical revision of the manuscript for important intellectual content. DMS was involved in data acquisition, analysis and interpretation of patient data, manuscript drafting, and study design. RCC was involved in data acquisition, analysis and interpretation of patient data, manuscript drafting and study design. MR was involved in research-creation, design, analysis and interpretation of patient data, manuscript drafting and critical revision of the manuscript for important intellectual content. All authors have read and approved the final manuscript. All authors confirm the authenticity of all the raw data.

\section{Ethics approval and consent to participate}

The study has been approved by the Ethics Committee of the County Emergency Hospital of Sibiu, Romania (approval no. 24505)

\section{Patient consent for publication}

Written informed consent for publication was provided by the patient prior to the study start.

\section{Competing interests}

The authors declare that they have no competing interests.

\section{References}

1. Tran KD, Falcone MM, Choi DS, Goldhardt R, Karp CL, Davis JL and Galor A: Epidemiology of herpes zoster ophtalmicus: Recurrence and chronicity. Ophtalmology 123: 1469-1475, 2016.

2. Galil K, Choo PW, Donahue JG and Platt R: The sequelae of herpes zoster. Arch Intern Med 157: 1209-1213, 1997.

3. Shaikh $\mathrm{S}$ and Ta CN: Evaluation and management of herpes zoster ophthalmicus. Am Fam Physician 66: 1723-1730, 2002.

4. Dworkin RH, Johnson RW, Breuer J, Gnann JW, Levin MJ, Backonja M, Betts RF, Gershon AA, Haanpaa ML, McKendrick MW, et al: Recommendations for the management of herpes zoster. Clin Infect Dis 44 (Suppl 1): S1-S26, 2007.

5. Wiafe B: Herpes zoster ophthalmicus in HIV/AIDS. Community Eye Health 16: 35-36, 2003.
6. Opstelten W and Zaal MJ: Managing ophthalmic herpes zoster in primary care. BMJ 331: 147-151, 2005.

7. Long MD, Martin C, Sandler RS and Kappelman MD: Increased risk of herpes zoster among 108604 patients with inflammatory bowel disease. Aliment Pharmacol Ther 37: 420-429, 2013.

8. Korber A, Franckson T, Grabbe S and Dissemond J: Ambilateral reactivation of herpes zoster V2 following cataract operation of both eyes. J Eur Acad Dermatol Venereol 21: 712-713, 2007.

9. Atzori L, Ferreli C, Zucca M, Fanni D and Aste N: Facial cellulitis associated with complicating ophthalmic herpes zoster. Dermatol Online J 10, 2004.

10. Lavaju P, Badhu BP and Shah S: Herpes zoster ophthalmicus presenting as orbital abscess along with superior orbital fissure syndrome: A case report. Indian J Ophthalmol 63: 733-735, 2015.

11. Anthony CL, Bavinger JC and Yeh S: Advances in the diagnosis and management of acute retinal necrosis. Ann Eye Sci 5: 28, 2020.

12. Zaal MJ, Völker-Dieben HJ and D'Amarao J: Prognostic value of Hutchinson's sign in acute herpes zoster ophthalmicus. Graefes Arch Clin Exp Ophthalmol 241: 187-191, 2003.

13. Scott FT, Leedham-Green ME, Barrett-Muir WY, Hawrami K, Gallagher WJ, Johnson R and Breuer J: A study of shingles and the development of postherpetic neuralgia in East London. J Med Virol 70 (Suppl 1): S24-S30, 2003.

14. Rousseau A, Bourcier T, Colin J and Labetoulle M: Herpes zoster ophthalmicus-diagnosis and management. US Ophthalm Rev 6: 119-124, 2013.

15. Liesegang TJ: Herpes zoster ophthalmicus natural history, risk factors, clinical presentation, and morbidity. Ophthalmology 115 (Suppl 2): S3-S12, 2008.

16. Gnann JW Jr and Whitley RJ: Clinical practice. Herpes zoster. N Engl J Med 347: 340-346, 2002.

17. Kausar S, Said Khan F, Ishaq Mujeeb Ur Rehman M, Akram M, Riaz M, Rassol G, Hamid Khan A, Saleem I, Shamim S and Malik A: A review: Mechanism of action antiviral drugs. Int J Immunopathol Pharmacol 35: 20587384211002621, 2021.

18. Cheema HS, Diedrich AM, Kyne BM and Toeque M: A case of tri-segmental cranial nerve V herpes zoster. IDCases 18: e00642, 2019.

19. Srinivasan S, Ahn G and Anderson A: Meningoencephalitiscomplicating herpes zoster ophthalmicus infection. J Hosp Med 4: E19-E22, 2009.

20. Harthan JS and Borgman CJ: Herpes zoster ophthalmicus-induced oculomotor nerve palsy. J Optom 6: 60-65, 2013.

21. Khalafallah AA, Woodgate M, Koshy K and Patrick A: Ophthalmic manifestations of herpes zoster virus in patients with multiple myeloma following bone marrow transplantation. BMJ Case Rep 2013: bcr2012007625, 2013.

22. Rajkumar A and Baum E: Cerebral venous sinus thrombosis resulting from herpes zoster infection in an older adult. Ann Longterm Care Clin Care Aging 24: 27-30, 2016.

23. Letchuman V and Donohoe CD: Brainstem and cerebellarinvolvement in Ramsay Hunt syndrome. Case Rep Otolaryngol 2019: 7605056, 2019.

24. Mercier T, Deslypere G and Nackaerts K: Ramsay Hunt syndrome: A rare complication of herpes zoster infection in a lung cancer patient. Acta Clin Belg 74: 355-358, 2019.

25. Chen I, Fohtung RB, Oughli HA, Bauer R, MattarC, Powderly WG and Thoelke MS: Concurrent Ramsay Hunt syndrome and disseminated herpes zoster in a patient with relapsed chronic lymphocytic leukemia. IDCases 8: 79-82, 2016.

26. Pointdujour R, Temnogorod J, Mancini R, Chang SH, Esmaeli B and Shinder R: Acute orbital syndrome in herpes zoster ophthalmicus. Invest Ophthalmol Vis Sci 55: 4082, 2014.

27. Sanghvi CA, Leatherbarrow B and Ataullah S: Cicatricial ectropion due to herpes zoster ophthalmicus. J Postgrad Med 52: 153-154, 2006.

28. Birlutiu V, Birlutiu RM, Baicu M and Iancu GM: A case report of double etiology of ecthyma gangrenosum: Pseudomonas aeruginosa and Enterococcus faecalis in an immunocompromised child occurred during influenza evolution. Medicine (Baltimore) 98: e15651, 2019.

29. Shin HM, Lew H and Yun YS: A case of complete ophthalmoplegia in herpes zoster ophthalmicus. Korean J Ophthalmol 19: 302-304, 2005

30. Lee JH, Heo HJ, Kim KM, Lee HG, Baek SM and Jung DW: Herpes zoster in the ophthalmic branch of the trigeminal ganglia obscuring cavernous sinus thrombosis due to streptococcus constellatus subsp. Constellatus-a case report. Anesth Pain Med (Seoul) 15: 205-208, 2020. 
31. Trottini $\mathbf{M}$ and DelGiofice $\mathrm{M}$ : When herpes causes 3rd nerve palsy, patients and practitioners suddenly have to deal with multiple issues. Rev Optom 153: 24-25, 2016.

32. Okuniki Y, Sakai J, Kezuka T and Goto H: A case of herpes zoster uveitis with severe hyphema. BMC Ophthalmol 14: 74 , 2014.

33. Akpek EK and Gottsch JD: Herpes zoster sine herpete presenting with hyphema. Ocul Immunol Inflamm 8: 115-118, 2000.

34. Arvinth R, Zahari M and Reddy SC: Herpes zoster anterior uveitis and hyphema. Eur J Medical Health Sci 3: 1-3, 2021.

35. Hayasaka S, Watanabe M, Yamamoto Y, Noda S, Sekimoto M and Setogawa T: Herpes zoster ophthalmicus complicated by hyphema and hemorrhagic glaucoma. Ophtalmologica 196: $185-187,1988$
36. Katherine SBH, Ngim YS, Juliana J and Ramli N: Herpes zoster keratouveitis with hypopyon and hyphema. Taiwan J Ophthalmol 10: 54-57, 2020.

37. Lee CY, Tsai HC, Jung Lee SS and Chen YS: Orbital apex syndrome: An unusual complication of herpes zoster ophthalmicus. BMC Infect Dis 15: 33, 2015.

38. Forbes HJ, Bhaskaran K, Thomas SL, Smeeth L, Clayton T, Mansfield K, Minassian C and Langan SM: Quantification of risk factors for postherpetic neuralgia in herpes zoster patients: A cohort study. Neurology 87: 94-102, 2016.

(c) (3) $\Theta$ This work is licensed under a Creative Commons Attribution-NonCommercial-NoDerivatives 4.0 International (CC BY-NC-ND 4.0) License. 